\title{
DA CAPACIDADE JURÍDICA DAS PESSOAS NATURAIS ${ }^{1}$
}

\section{ON THE LEGAL CAPACITY OF NATURAL PERSONS}

\author{
JÖRG NEUNER ${ }^{2}$
}

\begin{abstract}
RESUMO: O anencéfalo - que, de acordo com uma recente decisão do Supremo Tribunal Federal brasileiro, não consubstancia um objeto material apto a ensejar um aborto criminalmente proibido - encontra-se, na Alemanha, tanto sob proteção penal como constitucional. No direito civil alemão, ele é considerado juridicamente capaz, porquanto apenas importa o término do nascimento e basta a comprovação de uma única função vital. Com respeito à integridade corporal, o nascituro já é parcialmente capaz do ponto de vista jurídico. De modo correspondente ao início da capacidade jurídica, afigura-se decisiva para seu término a paralização da última função vital central.
\end{abstract}

PALAVRAS-CHAVE: Anencéfalo; Capacidade Jurídica; Nascituro; Capacidade Jurídica Parcial.

ABSTRACT: The anencephalus - not classified as an object of a punishable termination of pregnancy according to an actual judgment of the Brazilian Federal Supreme Court - in Germany is protected by the criminal and the constitutional law. The german civil law considers the anencephalus to have legal capacity, as merely the completion of birth is relevant and the detection of one single vital parameter suffices. Regarding to the physical integrity the nasciturus already has partial legal capacity. Corresponding to the beginning of the legal capacity the failure of the last vital parameter determines its ending.

KEYWORDS: Anencephalus; Legal Capacity; Nasciturus; Partial Legal Capacity.

SUMÁRIO: Introdução; I. O Início da Capacidade Jurídica; II. O Fim da Capacidade Jurídica; III. Ampliações da Proteção; IV. Teses; Referências.

SUMMARY: Introduction; I. The Beginning of Legal Capacity; II. The End of Legal Capacity; III. Protection Increases; IV. Theses; References.

\footnotetext{
Artigo recebido em 17.10.2012. Artigo aceito para publicação em 19.11.2012 mediante convite.

${ }^{1}$ Artigo traduzido por Pedro Scherer de Mello Aleixo que agradece a Jorge Cesa Ferreira da Silva por suas valiosas sugestões de melhorias na tradução.

2 Professor Catedrático de Direito Civil, Direito do Trabalho, Direito Comercial e Filosofia do Direito junto à Universidade de Augsburg.
} 


\section{INTRODUÇÃO}

O Supremo Tribunal Federal brasileiro, em sua recente decisão de 12 de abril de 2012, declarou admissível a interrupção da gravidez no caso de anencefalia fetal. ${ }^{3}$ Ao passo que, até então, de acordo com o artigo 128 do Código Penal brasileiro, abortos apenas eram permitidos havendo risco de morte para a grávida ou gravidez decorrente de estupro, foi doravante adicionada uma terceira constelação excepcional, que leva em consideração o nascituro e seu distúrbio cerebral. É bem verdade que, flanqueando as malformações no cérebro da criança, o Tribunal também argumenta com os direitos fundamentais da mulher, mas afigura-se característico que o Tribunal apenas considera os direitos da mulher como dotados de supremacia pelo fato de o nascituro padecer de anencefalia e não, v. g., de outros defeitos do tubo neural, como espinha bífida aberta, síndrome de Down ou outras graves malformações. A diferença decisiva é vista, por conseguinte, nas atividades cerebrais faltantes, as quais impedem que o anencéfalo se torne uma pessoa e se contrapõem a um respectivo direito à vida.

Em contrapartida, de acordo com a doutrina dominante na Alemanha, um anencéfalo pode ser objeto material de um aborto proibido, assim como, v. g., um embrião portador de trissomia regular do cromossomo 16, cujo nascimento com vida está de antemão descartado. ${ }^{4} \mathrm{~A}$ atividade cerebral é vista como irrelevante para a questão de se o embrião merece proteção já pelo fato de o cérebro não poder se desenvolver antes do trigésimo segundo dia posterior à concepção, ${ }^{5}$ sendo o feto, por outro lado, já protegido desde a nidação. ${ }^{6}$ Vindo uma criança anencéfala com vida ao mundo, intervém, além disso, a proteção jurídico-penal da vida. ${ }^{7}$ De um ponto de vista geral, todavia, a situação jurídica prevalente na Alemanha afigura-se claramente mais liberal do que no Brasil. Embora um aborto acompanhado de indicação embriopática não seja livre de punição na Alemanha, ele geralmente não é punido quando não tenham transcorrido mais de doze semanas desde a concepção e a grávida tenha se submetido a uma conversa de orientação (§ 218, alínea a, 1, Código Penal alemão). Além disso, um aborto já não é ilegal quando há risco de grave prejuízo ao estado de saúde corporal ou psíquico da grávida ${ }^{8}-$

\footnotetext{
${ }^{3}$ ADPF 54/DF.

${ }^{4}$ Cf. Merkel, in: Kindhäuser/Neumann/Paeffgen, StGB, 3. ed., 2010, § 218, números de margem 18 ss., 24 ss.; Neumann, op. cit., nota preliminar ao § 211, número de margem 32; Isemer/Lilie, Rechtsprobleme bei Anencephalen, MedR, 1988, p. 66 ss. (p. 69).

${ }^{5} \mathrm{~V}$., de maneira mais pormenorizada, Harding, The Brain, in: Reed/Claireaux/Cockburn, Diseases of the Fetus and Newborn: Pathology, Imaging, Genetics and Management, 2. ed., 1994, p. 413 ss. (p. 413).

${ }^{6}$ Cf. Merkel, in: Kindhäuser/Neumann/Paeffgen, StGB, 3. ed., 2010, § 218, número de margem 20.

${ }^{7}$ Cf. BGHSt (Coletânea das decisões do Supremo Tribunal alemão em matéria penal) 10, p. 291 ss. (292 ss.); Isemer/Lilie, Rechtsprobleme bei Anencephalen, MedR, 1988, p. 66 ss. (p. 68); Wessels/Hettinger, Strafrecht, Besonderer Teil 1, 33. ed., 2009, § 1, número de margem 26.

${ }^{8}$ Segundo um estudo internacional (levando em conta especialmente a Europa e os Estados Unidos), $76,9 \%$ das mães decidem-se por um aborto no caso de anencefalia (em se tratando de trissomia do cromossomo 21, são 91,9\%); cf. Lenhard, Der Einfluss pränataler Diagnostik und
} 
o que é frequentemente afirmado no caso de anencefalia fetal (§ 128, alínea a, 2 , Código Penal alemão). ${ }^{9}$

Não quero, todavia, me ocupar, na sequência, com a problemática jurídico-penal ou constitucional do aborto. Muito menos quero adentrar no difícil debate basilar a respeito do status moral e jurídico dos embriões. ${ }^{10} \mathrm{Meu}$ interesse consiste antes em investigar, impulsionado pela decisão do STF, a posição jurídica do anencéfalo no contexto específico do direito civil. Uma análise mais aproximada permite, todavia, depreender que se trata apenas de um fragmento de um complexo maior de problemas, que retorna de maneira análoga ao final da vida, no que diz respeito à determinação do momento da morte segundo o conceito de morte cerebral. Quero, por isso, falar de maneira bastante geral a respeito da capacidade jurídica das pessoas naturais e levar em consideração os novos conhecimentos e progressos alcançados na medicina. ${ }^{11}$ Neste ponto só posso, naturalmente, esboçar a situação no direito alemão, não obstante haja diversos paralelos com as regulamentações previstas nos artigos $1^{\circ}$ e seguintes do Código Civil brasileiro.

A questão inicial a respeito da posição do anencéfalo no direito civil não consite em uma temática distanciada da prática e puramente acadêmica. Isso já demonstra a estatística, segundo a qual de aproximadamente mil nascimentos há um caso de anencefalia. ${ }^{12}$ É bem verdade que muitas crianças portadoras de anencefalia morrem já dentro do útero ou durante o parto, mas inúmeras frequentemente ainda sobrevivem por diversas horas ou dias após o nascimento. ${ }^{13}$ É conhecido o caso descrito por Monnier e Willi, no qual uma

selektiven Fetozids auf die Inzidenz von Menschen mit angeborener Behinderung, Heilpädagogische Forschung 29, 2003, p. 165 ss.

${ }^{9}$ Cf. Lackner/Kühl, StGB, 27. ed., 2011, número de margem 5, com documentação comprobatória adicional.

${ }^{10}$ V. a respeito, v. g., Damschen/Schönecker, Der moralische Status menschlicher Embryonen Pro und contra Spezies-, Kontinuums-, Identitäts- und Potentialitätsargument, 2003; v. especialmente com respeito à deficiência mental também Wasserman/Asch/Blustein/Putnam, Cognitive Disability and Moral Status, in: Stanford Encyclopedia of Philosophy, 6. Juli 2012.

${ }^{11}$ Por capacidade jurídica compreende-se a capacidade de uma pessoa ser sujeito de relações jurídicas, ou seja, titular de direitos ou destinatário de deveres jurídicos. Desta posse de direitos e deveres há de ser distinguida a capacidade de fato, que abrange a competência de levar a cabo consequências jurídicas por intermédio da própria atuação. Uma criança pequena é, assim, v. g., juridicamente capaz, mas não possui capacidade negocial, delitual ou de consentimento. V., de maneira mais pormenorizada, Wolf/Neuner, BGB AT, 10. ed. 2012, § 11, número de margem 1 , § 12, número de margem 1.

${ }^{12} \mathrm{Cf}$. Obeidi/Russell/Higgins/O'Donoghue, The natural history of anencephaly, Prenat. Diagn. 30, 2010; p. 357 ss. (p. 357), com documentação comprobatória adicional.

${ }_{13} \mathrm{~V}$., de maneira mais pormenorizada, Jaquier/Klein/Boltshauser, Spontaneous pregnancy outcome after prenatal diagnosis of anencephaly, British Journal of Obstetrics and Gynaecology, 113,2006 , p. 951 ss. (cento e cinqueta e três (72\%) das crianças portadoras de anencefalia (211 gravidezes) nasceram com vida, destas 103 (67\%) morreram dentro de 24 horas, mas 6/211 sobreviveram 6 ou mais dias (máximo de 28 dias)); Obeidi/Russell/Higgins/O'Donoghue, The natural history of anencephaly, Prenat. Diagn. 30, 2010, p. 357 ss. (p. 358 s.: de 26 fetos, 6 morreram dentro do útero, 9 durante o parto, e em 11 houve a morte no estágio neo-natal com um tempo de sobrevivência entre 10 minutos e 8 dias). 
criança portadora de anencefalia completou cinquenta e sete dias de vida. ${ }^{14}$ Do Estado de São Paulo foi até mesmo noticiado a respeito de uma menina chamada Marcela, que completou um ano e meio, não obstante se tenha aparentemente tratado de um caso da chamada meroencefalia (anencephalia partialis). ${ }^{15}$ Do ponto de vista do direito civil, surge, após o nascimento dessas crianças, a questão a respeito da respectiva capacidade jurídica, especialmente acerca do seu status no plano do direito de família e da proteção a ser em princípio a elas concedida no plano da responsabilidade civil. De elevada relevância prática afigura-se, além disso, a posição no plano do direito sucessório, na medida em que a criança portadora de anencefalia ainda não estava viva no momento da abertura da sucessão (v. g. por ocasião da morte do pai), mas já fora concebida e vem ao mundo por pouco tempo, sendo então eventualmente tratada como se tivesse nascido antes da abertura da sucessão.

\section{O INÍCIO DA CAPACIDADE JURÍDICA}

$\mathrm{Na}$ Alemanha, a capacidade jurídica começa, segundo o $\S 1^{\circ}$ do BGB, com a conclusão do nascimento. O nascimento é concluído com a saída completa da criança do útero, sem necessidade de que haja o corte do cordão umbilical. ${ }^{16}$ De maneira reveladora, o status embrionário termina mais cedo no direito penal, com o início das dores de dilatação ou com o início da incisão cesariana, de modo a levar em conta a elevada situação de perigo enfrentada pela criança durante 0 parto. ${ }^{17}$ No direito civil, domina, em contrapartida, o pensamento de que somente com a conclusão do nascimento pode o ser humano existir como organismo independente da mãe. Esta diferenciação entre direito penal e civil mostra de maneira exemplar que o conceito de "vida" não deve ser definido juridicamente de maneira uniforme, mas depende de considerações normativas e das especificidades do respectivo campo jurídico.

A capacidade jurídica pressupõe, além disso, que a criança esteja viva no momento da saída completa do útero. ${ }^{18}$ Isto também não constitui uma obviedade.

\footnotetext{
14 Monnier/Willi, Die integrative Tätigkeit des Nervensystems beim meso-rhombo-spinalen Anencephalus (Mittelhirnwesen), Monatsschrift für Psychiatrie und Neurologie, 126, 1953, p. 239 ss. (p. 240, p. 242 ss.: "No exame realizado no $53^{\circ}$ dia de vida observa-se, logo após a remoção das roupas, como a criança levanta a cabeça, conduz as mãos com os punhos cerrados até a boca e boceja levemente. [...] Tocando-se a sola do pé com gelo, o menino se encolhe e recolhe a perna. [...] Com suco de limão dissolvido, o menino franze o rosto e coloca até mesmo a mão na frente da boca. [...] O menino faz frequentemente movimentos espontâneos - para a frente e para trás - com a cabeça, movimentos estes acompanhados por movimentos dos lábios e da língua. [...] Ocasionalmente o menino grita de modo estridente. [...] O reflexo de segurar a mão afigura-se bastante vigoroso em ambos os lados e frequente...").

${ }^{15}$ Cf. voto do Min. Marco Aurélio Mello na ADPF 54/DF, p. 51 ss.

${ }^{16}$ Exposição de Motivos I, p. 28; Schmitt, Münchener Kommentar zum BGB, vol. 1, 6. ed., 2012, $\S 1$, número de margem 15.

${ }_{17}$ BGHSt 32, p. 194 ss. (p. 195 s.); Jähnke/Laufhütte/Odersky, StGB, vol. 5, 11. ed., 2005, nota anterior ao § 211, número de margem 3; Herzberg/Herzberg, Der Beginn des Menschseins im Strafrecht: Die Vollendung der Geburt, JZ, 2001, p. 1106 ss. (p. 1109).

${ }_{18} \mathrm{~V}$. a respeito, também, de modo mais pormenorizado, Roller, Die Rechtsfähigkeit des Nasciturus, 2012, 6a parte, B.
} 
Há, assim, outros ordenamentos jurídicos nos quais a criança precisa ter sobrevivido por um determinado lapso temporal. De acordo com a versão antiga do artigo 30 do Código Civil espanhol, alterada todavia em 2011 (de modo análogo à regulamentação alemã), ${ }^{19}$ a criança precisa, por exemplo, ter sobrevivido vinte e quatro horas desde o nascimento e apresentar um "semblante humano". Na Alemanha, ambos pressupostos são desnecessários. Nos materiais legislativos diz-se, pelo contrário, de modo expresso que mesmo um chamado "monstro" não está excluído da capacidade jurídica. ${ }^{20}$ A título de fundamentação é aduzido que a delimitação é demasiado incerta, "de modo que, com base nela, uma diferenciação tão fatídica pudesse ser construída". ${ }^{21}$ Esta ponderação vale especialmente também para as crianças portadoras de anencefalia, nas quais, de regra, faltam em grande parte a fontanela, as meninges e o telencéfalo; o tronco encefálico pode, todavia, estar tão avançado do ponto de vista funcional que uma respiração própria provisória se afigura possível. De modo correspondente à intensidade da malformação cerebral, podem se manifestar, por vezes, também reações comportamentais como engolir, bocejar, chupar o polegar e até mesmo manifestações de dor. ${ }^{22}$ Recém-nascidos portadores de anencefalia não são, portanto, criaturas completamente desprovidas de cérebro, de modo que sequer se questiona se a existência humana pressupõe um cérebro, mas no máximo acerca do quantum necessário. Simplesmente determiná-lo já está, todavia, atrelado a enormes dificuldades de delimitação e a um elevado potencial de discriminação, de modo que o legislador acertadamente equipara do ponto de vista jurídico todos os nascimentos com vida e atribui capacidade jurídica completa às crianças portadoras de anencefalia, bem como a outros recém-nascidos com prognósticos sem perspectiva de cura. Crianças portadoras de anencefalia também precisam, por isso, ser inscritas no registro de nascimentos. O pressuposto legal do nascimento com vida, ensejador de um dever de registro, é tão somente que a criança, "após a saída do útero, tenha apresentado batimentos cardíacos, pulsação no cordão umbilical ou respiração pulmonar natural" ${ }^{23}$

\section{O FIM DA CAPACIDADE JURÍDICA}

Diferentemente do início da capacidade jurídica, seu fim não está regulamentado de maneira pormenorizada no BGB. Os autores do BGB de 1900 pressupuseram a morte como critério evidente. ${ }^{24} \mathrm{Em}$ que momento

\footnotetext{
${ }^{19}$ Boletim Oficial do Estado Espanhol, n 175/2011, de 22.07.2011.

${ }^{20}$ Exposição de Motivos I, p. 29.

${ }^{21}$ Exposição de Motivos I, p. 29.

${ }^{22}$ Cf. Zieger, Wie viel Gehirn braucht ein Mensch? Anmerkungen zum Anencephalie-Problem aus beziehungsmedizinischer Sicht, in: Laubenstein/Lamers/Heinen, Basale Stimulation, kritischkonstruktiv, 2006, p. 267 ss. (p. 274 ss.); Schroth/König/Gutmann/Oduncu, TPG, 2005, introdução, número de margem 97; Isemer/Lilie, Rechtsprobleme bei Anencephalen, MedR 1998, p. 66 ss. (p. 67); v. também acima, nota de rodapé 12.

${ }^{23} \S 31,1$, do Regulamento para a Implementação da Lei sobre o Estado Civil.

${ }^{24}$ Protocolo I, p. 4; Protocolo VI, p. 106.
} 
ocorre a morte não é, todavia, de modo algum evidente segundo o estágio atual de conhecimento, uma vez não se tratar de um acontecimento abrupto, mas sim de um processo no qual há de se diferenciar entre a morte dos sistemas de órgãos individuais. Leva-se em consideração diferentes pontos de conexão, especialmente a morte do sistema cardiovascular e a morte cerebral.

A doutrina dominante no direito civil parte do critério da morte de todo o complexo cerebral, ${ }^{25}$ nos moldes em que ele é regulamentado como pressuposto para a retirada de órgãos na Lei de Transplantes alemã ( $\S 3^{\circ}$, par. $2, n^{\circ} 2$ ). O momento decisivo para fixação da morte no direito civil é, com isso, a completa perda de função por parte do cérebro. ${ }^{26}$ Esta concepção afigura-se consequente e acertada sobretudo na medida em que seres humanos em estado vegetativo persistente ou permanente (persistent or permanent vegetative state) - nos quais, de maneira análoga às crianças portadoras de anencefalia, apenas uma parte do cérebro, nomeadamente a função do telencéfalo, está afetada - não são por ela abrangidos. ${ }^{27}$ Assim, especialmente a capacidade de consciência não constitui pressuposto para a capacidade jurídica.

Também com respeito à determinação do momento da morte afigura-se, todavia, questionável se se pode, em grande parte, transferir a definição de modo irrefletido de algum outro campo jurídico para o direito civil. Ao passo que a Lei de Transplantes regulamenta apenas as possibilidades especiais de retirada de órgãos, o direito civil possui uma dimensão - pessoal e patrimonial - essencialmente mais abrangente. Pergunta-se, assim, se no direito civil não deve ocorrer, além da morte cerebral, adicionalmente também a morte cardiovascular para que seja perdida a capacidade jurídica.

A problemática se deixa ilustrar de maneira bastante plástica com um caso alemão, no qual uma grávida foi vítima de um grave acidente de trânsito. ${ }^{28}$ Pouco depois da chegada da grávida ao hospital, foi constatada sua morte cerebral, mas sua circulação e respiração foram mantidas artificialmente por um longo período a fim de salvar a vida da criança. Em uma tal morte cerebral dissociada parece pouco adequado considerar a mulher morta do ponto de vista do direito civil apesar de ela continuar desempenhando seu papel materno e, por conta da proibição em princípio existente em relação ao aborto, haver até mesmo o dever de manter suas funções vitais. Diante deste dever de cuidado materno e do engajamento social da mãe em prol de sua

\footnotetext{
${ }^{25}$ Cf. apenas Palandt/Weidlich, BGB, 71. ed., 2012, § 1922, número de margem 2, com documentação comprobatória adicional.

${ }^{26}$ Crianças portadoras de anencefalia são regularmente excluídas como doadoras de órgãos já pelo fato de a respectiva morte cerebral não poder ser diagnosticada; v., de maneira mais pormenorizada, Karpf, Transplantationen von Organen Verstorbener in Österreich und Großbritannien, 2010, p. 44 s.

${ }^{27}$ Cf. apenas Schroth/König/Gutmann/Oduncu, TPG, 2005, introdução, números de margem 94 s.

${ }^{28}$ Cf. AG (Tribunal de comarca) Hersbruck, NJW 1992, p. 3245.
} 
criança e da sociedade, parece inadequado deixar a capacidade jurídica terminar já com a morte cerebral. Ela expira, corretamente, após o término da manutenção das funções cardiovasculares por meio da medicina intensiva. Isso tem por consequência no direito civil que a mãe, uma vez ocorrida a morte cerebral, não se torna subitamente um mero objeto para gestar o nascituro - objeto este passível de proteção post mortem -, mas, de modo comparável a alguém em estado vegetativo persistente ou permanente, há de continuar sendo tratada como um sujeito de direitos. Além desse aspecto relativo aos direitos de personalidade, a grávida diagnosticada com morte cerebral também é protegida na perspectiva patrimonial, podendo v. g. receber alimentos e não perdendo a capacidade de herdar. Além disso, os custos para manutenção do acompanhamento médico da mãe permanecem, na perspectiva do seguro-saúde, custos originários de gravidez.

De modo similar a uma grávida diagnosticada com morte cerebral, um doador de órgãos também ainda se encontra em interação social direta quando disponibiliza a outros partes de seu corpo. Ao mesmo tempo, ele age de maneira altruísta e no interesse geral da sociedade. Por isso, parece ser aqui igualmente inadequado aceitar o fim da capacidade jurídica já com a ocorrência da morte cerebral. Ao invés disso, afigura-se adequado fortalecer a autonomia do doador de órgãos, valorando-se intervenções indevidas v. g. com respeito a determinadas retiradas de órgãos não consentidas como lesões corporais e violações de direitos de personalidade. Segundo o direito alemão, isso teria, a seu turno, por consequência uma pretensão indenizatória na forma de danos morais, a qual - nos mesmos moldes que no caso de pacientes em coma - não pressupõe a respectiva consciência e desenvolve uma eficácia preventiva no sentido de proceder-se com o corpo de um paciente com morte cerebral somente de acordo com sua concordância prévia. Por isso, pode inclusive representar um incentivo - socialmente desejável - para a doação de órgaos quando se concebe a morte civil somente com a paralização irreversível da função cardiovascular. Em perspectiva patrimonial parece também apenas consequente assegurar ao paciente com morte cerebral seu status pleno em sede de direito civil até o término do tratamento de medicina intensiva. Diferentemente de um paciente em estado vegetativo persistente ou permanente, o doador de órgãos tem suas funções cerebrais - é bem verdade - completamente extintas; ele, todavia, ainda está em condições de disponibilizar seu corpo para a sociedade, merecendo, assim, em contrapartida, ainda o reconhecimento como sujeito de direito. Embora também sejam imagináveis, além disso, constelações nas quais a morte clínica seja adiada por motivos indevidos, v. g. a fim de causar o vencimento de um prazo, o direito civil oferece para isso corretivos ante a abusos.

Em uma visão de conjunto, a capacidade jurídica das pessoas naturais termina, assim, somente após a antiga máxima de conhecimento "tres sunt atria mortis", ou seja, com a paralização conjunta das funções cardíacas, 
respiratórias e cerebrais. ${ }^{29}$ Esta exigência cumulativa afigura-se nada mais do que consequente também do ponto de vista sistemático: do mesmo modo como a capacidade jurídica inicia já com a comprovação de uma única função vital, termina ela somente com a paralização da última função vital central.

\section{AMPLIAÇÕES DA PROTEÇÃO}

Por implicação decorrente das regulamentações a respeito da capacidade jurídica, entende a doutrina dominante que tanto o nascituro como o falecido não possuem capacidade jurídica, embora ambos não estejam postos em situações desprovidas de proteção.

\section{A posição jurídica do falecido}

É bem verdade que o ser humano perde seu status de sujeito de direito com a morte, mas continuam existindo deveres de proteção com respeito ao corpo e à personalidade de resto existente.$^{30} \mathrm{~A}$ proteção se dirige v. g. contra manifestações depreciativas relativas ao falecido, falsificação póstuma de quadros de um pintor famoso (Emil Nolde) ${ }^{31}$ ou a caracterização de mercadorias com o nome de uma atriz já falecida (Marlene Dietrich) ${ }^{32}$.

Uma tal proteção post mortem da personalidade é, em parte, rejeitada, sendo somente os parentes remanescentes considerados como violados em seus próprios direitos gerais de personalidade. ${ }^{33}$ Esta chamada teoria do parentesco conduz, todavia, a lacunas de proteção quando o falecido já não mais possui parentes ou a violação post mortem a direitos de personalidade seja justamente oriunda de seus parentes. Por isso, é postulada na literatura uma capacidade jurídica post mortem parcial, ${ }^{34}$ mas assim o direito de personalidade ficaria de modo definitivo e para sempre desprovido de sujeito. Um tal direito duradouro desprovido de sujeito afigura-se, todavia, fundamentalmente estranho ao ordenamento jurídico alemão e contradiz a ideia de que relações jurídicas, por conta de seu caráter normativo, apenas podem existir entre pessoas. A maneira correta de proceder é, ao invés disso, partir do pressuposto de um modelo assemelhado à propriedade fiduciária,

\footnotetext{
${ }^{29}$ V. também Roller, Die Rechtsfähigkeit des Nasciturus, 2012, 6a parte, C. I. 4.

${ }^{30}$ Cf. Jauernig/Teichmann, BGB, 14. ed., 2011, número de margem 68, com documentação comprobatória adicional; Schack, Weiterleben nach dem Tode - juristisch betrachtet, JZ, 1989, p. 609 ss.

${ }^{31}$ BGHZ (Coletânea das decisões do Supremo Tribunal alemão em matéria civil) 107, p. 384 ss.

${ }^{32}$ BGHZ 143, p. 214 ss.

${ }^{33}$ Bizer, Postmortaler Persönlichkeitsschutz? - Rechtsgrund und Länge der Schutzfristen für personenbezogene Daten Verstorbener nach den Archivgesetzen des Bundes und der Länder, NVwZ 1993, p. 653 ss. (p. 655); Stein, Der Schutz von Ansehen und Geheimsphäre Verstorbener, FamRZ 1986, p. 7 ss. (p. 9); Taupitz, Privatrechtliche Rechtspositionen um die Genomanalyse: Eigentum, Persönlichkeit, Leistung, JZ 1992, p. 1089 ss. (p. 1094); v. a respeito também Claus, Postmortaler Persönlichkeitsschutz im Zeichen allgemeiner Kommerzialisierung, 2004, p. 66 ss., bem como Luther, Postmortaler Schutz nichtvermögenswerter Persönlichkeitsrechte, 2009, p. 88 ss., com documentação comprobatória adicional.

${ }^{34}$ Schmitt, Münchener Kommentar zum BGB, vol. 1, 6. ed., 2012, § 1, número de margem 55; Müller, Postmortaler Rechtsschutz - Überlegungen zur Rechtssubjektivität Verstorbener, 1996, p. 249 ss.
} 
que estabelece deveres jurídicos gerais também em favor de bens jurídicos que não pressuponham um sujeito de direito. Para zelar pelos direitos post mortem afigura-se em primeira linha legitimado aquele que para isso for nomeado pelo falecido e, alternativamente, os parentes. ${ }^{35}$

A título de consequências jurídicas interessam sobretudo direitos de abstenção e de revogação. Pretensões de danos morais estão fora de questão para a doutrina dominante, porquanto não mais se afigura possível oferecer ao falecido uma reparação. ${ }^{36} \mathrm{~A}$ jurisprudência diferencia, de resto, elementos ideais e comerciais atinentes ao direito geral de personalidade. A proteção dos interesses ideais cabe ao legitimado para sua defesa (seguidamente aos parentes). ${ }^{37}$ Os elementos patrimonais são, em contrapartida, passíveis de ser herdados, de modo que os herdeiros podem fazer valer especialmente pretensões de indenização (v. g. com respeito à utilização do nome do falecido para fins comerciais). ${ }^{38}$

\section{A posição jurídica do nascituro}

Com respeito à posição jurídica do nascituro, pode-se distinguir entre a proteção do patrimônio e a da integridade. ${ }^{39}$

A proteção do patrimônio é assegurada sobretudo por meio da capacidade de herdar (§ 1923, par. 2, BGB), da possibilidade de um contrato em benefício de terceiros ( $\S 331$, par. 2, BGB; v. g. um seguro de vida), bem como, no âmbito do direito da responsabilidade civil relativo a pretensões indenizatórias, contra aquele que matar alguém futuramente responsável por prestar alimentos ao nascituro ( $\S 844$, par. 2, frase 2, BGB). Pressuposto para tanto é, todavia, que a criança venha a nascer com vida. Somente a partir daí adquire ela as pretensões individuais.

Uma intervenção junto à integridade do nascituro pode acontecer não apenas por meio de influências externas, mas também especialmente mediante a aplicação de medicamentos defeituosos. Na Alemanha há sobretudo dois leading-cases. De um lado, o chamado caso Contergan, no qual foi recomendado a mulheres grávidas um medicamento tranquilizante e sonífero (talidomida) que causou graves malformações em mais de cinco mil crianças. ${ }^{40}$ No chamado caso Lues, foi transferido para uma mãe, um ano antes do

\footnotetext{
${ }^{35}$ Cf. Larenz/Canaris, Schuldrecht II/2, 13. ed., 1994, § 80, VI, 2 (p. 534 s.).

${ }^{36}$ OLG (Tribunal Superior Estadual) Bremen, VersR 2003, p. 779 (ainda com respeito à versão antiga do § 847 do BGB); Oetker, Münchener Kommentar zum BGB, vol. 2, 6. ed. 2012, § 253, número de margem 28; Huber, NK-BGB, Band 2/1, 2. ed., 2012, § 253, número de margem 41.

${ }^{37}$ BGH NJW 1996, p. 593 ss.; Rixecker, Münchener Kommentar zum BGB, vol. 1, 6. ed., 2012, suplemento ao § 12, número de margem 36; Koos, NK-BGB, vol. 1, 2. ed., 2012, § 12, número de margem 129.

${ }^{38}$ BGHZ 143, p. 214 ss. (p. 220 ss.); Prütting, in: Prütting/Wegen/Weinreich (orgs.), BGB, 7. ed., 2012, § 12, número de margem 33; Schönberger, Postmortaler Persönlichkeitsschutz, 2011, p. 139 s.; Gregoritza, Die Kommerzialisierung von Persönlichkeitsrechten Verstorbener, 2003, p. 82 ss.

${ }^{39}$ Cf. também Wolf/Neuner, BGB AT, 10. ed., 2012, § 11, números de margem 11 ss., bem como, de modo mais pormenorizado, Roller, Die Rechtsfähigkeit des Nasciturus, 2012, 5 a parte.

${ }^{40}$ LG (Tribunal Regional) Aachen JZ 1971, p. 507 ss.
} 
nascimento de seu filho, sangue de um portador de sífilis, daí emergindo, como consequência, alguns meses depois da fertilização, uma transmissão diaplacentária da sífilis para o embrião. ${ }^{41}$ Neste segundo caso a atitude causadora do dano foi tomada, portanto, já antes da concepção. Em ambos os casos trata-se de um chamado delito que se protrai no tempo, que também é sancionado do ponto de vista da responsabilidade civil, assim como quando um medicamento defeituoso é fabricado antes de a criança ser concebida e posteriormente a ela administrado. ${ }^{42}$ De acordo com a doutrina dominante, as violações conduzem, todavia, a pretensões indenizatórias somente com a conclusão do nascimento. ${ }^{43}$

Essa remessa à conclusão do nascimento para o surgimento da pretensão parece, todavia, não mais ser apropriada diante dos progressos alcançados pela moderna medicina no campo da cirurgia fetal. Se for v. g. adotada uma intervenção minimamente invasiva em um embrião, afigura-se de difícil compreensão por que não deve caber à criança, desde o início, uma pretensão contra aquele que vier a lhe causar um dano, cabendo, ao invés disso, à mãe arcar com os custos, havendo o risco de que a criança não venha ao mundo com vida. Também com respeito à proteção do direito geral de personalidade, $v$. g. relativamente a afirmações inverídicas a respeito da descendência, seria inadequado assegurar a proteção somente a partir da conclusão do nascimento. ${ }^{44} \mathrm{O}$ modo correto de proceder consiste, assim, em partir de uma capacidade jurídica parcial do nascituro com respeito à proteção da integridade.

Ao invés de levar a cabo intervenções minimamente invasivas, é hoje em dia possível, do ponto de vista médico, operar o feto de modo aberto, ou seja, após a abertura do útero e da bolsa amniótica. É bem verdade que o nascituro é aqui separado da mãe, mas não se trata, do ponto de vista teleológico, de um nascimento, e sim de uma fase temporária voltada a devolver a criança para o ventre materno. Não se deve, portanto, partir de uma capacidade jurídica plena do nascituro também na perspectiva jurídico-patrimonial. A cirurgia fetal está naturalmente em seu estágio inicial e passará a ocupar o direito civil de maneira intensificada somente no futuro próximo.

\section{IV.TESES}

Essencialmente deixam-se resumir as seguintes teses:

1. O conceito de "vida" não deve ser definido de modo uniforme, mas depende de considerações normativas e das especificidades do respectivo campo jurídico.

2. Já é suficiente para o início da capacidade jurídica a comprovação de uma única função vital. Recém-nascidos anencéfalos, assim com outras

\footnotetext{
${ }^{41}$ BGHZ 8, p. 243 ss.

${ }^{42}$ Cf. Larenz/Canaris, Schuldrecht II/2, 13. ed., 1994, § 76, II, 1, h (p. 385).

${ }^{43} \mathrm{Cf}$. apenas Palandt/Sprau, BGB, 71. ed., 2012, § 823, número de margem 88.

${ }^{44}$ Em sentido contrário Staudinger/Hager, BGB, 13ª rev., 1999, § 823, C, número de margem 19.
} 
crianças recém-nascidas com prognósticos sem perspectiva de cura, são dotados de plena capacidade jurídica.

3. A capacidade jurídica termina somente com a paralização da última função vital central. O conceito de morte cerebral completa afigura-se (diferentemente do que no direito dos transplantes) inadequado.

4. O nascituro é, com respeito a sua integridade corporal, parcialmente capaz do ponto de vista jurídico.

\section{REFERÊNCIAS}

BIZER, Johann. Postmortaler Persönlichkeitsschutz? - Rechtsgrund und Länge der Schutzfristen für personenbezogene Daten Verstorbener nach den Archivgesetzen des Bundes und der Länder. NVwZ (Neue Zeitschrift für Verwaltungsrecht), 1993.

CLAUS, Sabine. Postmortaler Persönlichkeitsschutz im Zeichen allgemeiner Kommerzialisierung. Baden-Baden: Nomos, 2004.

DAMSCHEN, Gregor; SCHÖNECKER, Dieter. Der moralische Status menschlicher Embryonen - Pro und contra Spezies-, Kontinuums-, Identitäts- und Potentialitätsargument. Berlim: Valter De Gruyter, 2003.

GREGORITZA, Anna. Die Kommerzialisierung von Persönlichkeitsrechten Verstorbener. Berlim: Duncker \& Humblot, 2003.

HARDING. The Brain, in: REED, G. CLAIREAUX, A. COCKBURN, F. Diseases of the Fetus and Newborn: Pathology, Imaging, Genetics and Management, 2. ed., Boca Raton: CRC Press, 1995.

HERZBERG, Rolf; HERZBERG, Annika. Der Beginn des Menschseins im Strafrecht: Die Vollendung der Geburt. Juristen Zeitunz, 2001.

HUBER, Peter. BGB Kommentar. Band 2/1, 2. ed., Baden-Baden: Nomos, 2012.

ISEMER, Friedrich-Eckart; LILIE, H. Rechtsprobleme bei Anencephalen. MedizinRecht, p. 66-71. 1988.

JÄHNKE, Burkhard; LAUFHÜTTE, Heinrich Wilhelm; ODERSKY, Walter. Strafgesetzbuch. Leipziger Kommentar. vol. 5, 11. ed., Berlim: Valter De Gruyter, 2005.

JAQUIER, M. KLEIN, A. BOLTSHAUSER, E. Spontaneous pregnancy outcome after prenatal diagnosis of anencephaly. British Journal of Obstetrics and Gynaecology, 113, 2006.

JAUERNIG, Christian; TEICHMANN, Arndt. Bürgerliches Gesetzbuch. 14. ed., Munique: Beck Verlag, 2011.

KARPF, Stefanie. Transplantationen von Organen Verstorbener in Österreich und Großbritannien. Tese de Doutorado. Universidade de Viena, 2010. Disponível em: othes.univie.ac.at/8345/. Acessado em: 04 dez. 2012.

KOOS, Stefan. Bürgerliches Gesetzbuch. Nomos Kommentar. vol. 1, 2. ed., Baden-Baden: Nomos, 2012.

LACKNER, Karl; KÜHL, Kristian. Strafgesetzbuch: Kommentar. 27. ed., Munique: Beck, 2011.

LARENZ, Karl; CANARIS, Claus-Wilhelm von. Schuldrecht II/2, 13. ed., Munique: Beck, 1994. LENHARD, Wolfgang. Der Einfluss pränataler Diagnostik und selektiven Fetozids auf die Inzidenz von Menschen mit angeborener Behinderung, Heilpädagogische Forschung 29, 2003. 
LUTHER, Christoph. Postmortaler Schutz nichtvermögenswerter Persönlichkeitsrechte. Göttingen, V\&R Unipress, 2009.

MERKEL, in: KINDHÄUSER, Urs. NEUMANN, Ulfrid; PAEFFGEN, Hans-Ullrich. Strafgesetzbuch. 3. ed., Baden-Baden: Nomos, 2010.

MONNIER, M. WILLI, H. Die integrative Tätigkeit des Nervensystems beim mesorhombo-spinalen Anencephalus (Mittelhirnwesen). Monatsschrift für Psychiatrie und Neurologie. $\mathrm{n}^{\circ}$ 126, 1953.

MÜLLER, Knut. Postmortaler Rechtsschutz - Überlegungen zur Rechtssubjektivität Verstorbener. Frankfurt a.M.: Peter Lang, 1996.

OBEIDI, N. RUSSELL, N. HIGGINS, JR. O'DONOGHUE, K. The natural history of anencephaly, Prenat. Diagn. 30, 2010.

OETKER, Hartmut. Münchener Kommentar zum BGB. vol. 2, 6. ed., Munique: Beck, 2012. PALANDT, Otto; SPRAU, Hartwig. Bürgerliches Gesetzbuch. 71. ed., Munique: Beck, 2012. PALANDT, Otto; WEIDLICH, Dietmar. Bürgerliches Gesetzbuch. 71. ed., Munique: Beck, 2012.

PRÜTTING, Hanns in: PRÜTTING, Hanns; WEGEN, Gerhard; WEINREICH, Gerd. (orgs.). Bürgerliches Gesetzbuch. 7. ed., Neuwied: Luchterhand, 2012.

RIXECKER, Roland. Münchener Kommentar zum BGB. vol. 1, 6. ed., Munique: Beck, 2012. ROLLER. Die Rechtsfähigkeit des Nasciturus. 2012

SCHACK, Haimo. Weiterleben nach dem Tode - juristisch betrachtet. JuristenZeitung. V. 44. $n^{\circ}$ 13. 1989.

SCHMITT. Münchener Kommentar zum BGB. vol. 1, 6. ed., Munique: Beck, 2012.

SCHÖNBERGER, Simone. Postmortaler Persönlichkeitsschutz. Bielefeld: Gieseking Buchverlag, 2011.

SCHROTH, Ulrich; KÖNIG, Peter; GUTMANN, Thomas; ODUNCU, Fuat. Transplantationsgesetz Kommentar. Munique: Beck, 2005.

STAUDINGER, Julius von; HAGER, Johannes. Kommentar zum Bürgerlichen Gesetzbuch. 13 $3^{\mathrm{a}}$ rev. Berlim: Valter De Gruyter, 1999.

STEIN, Axeul. Der Schutz von Ansehen und Geheimsphäre Verstorbener. Zeitschrift für das gesamte Familienrecht mit Betreuungsrecht, Erbrecht, Verfahrensrecht, Öffentlichem Recht. 1986.

TAUPITZ, Jochen. Privatrechtliche Rechtspositionen um die Genomanalyse: Eigentum, Persönlichkeit, Leistung. JuristenZeitung. 1992.

WASSERMAN/ASCH/BLUSTEIN/PUTNAM, WASSERMAN, David; ASCH, Adrienne; BLUSTEIN, Jeffrey; PUTNAM, Daniel. Cognitive Disability and Moral Status. in: ZALTA, Edward N. (ed.) Stanford Encyclopedia of Philosophy. 2012.

WESSELS, Johannes; HETTINGER, Michael. Strafrecht. Besonderer Teil 1, 33. ed., Heidelberg: C.F. Müller, 2009.

WOLF, Manfred; NEUNER, Jörg. Allgemeiner Teil des Bürgerlichen Rechts. 10. ed., Munique: Beck, 2012.

ZIEGER, Andreas. Wie viel Gehirn braucht ein Mensch? Anmerkungen zum Anencephalie-Problem aus beziehungsmedizinischer Sicht, in: LAUBENSTEIN, Désirée; LAMERS, Wolfgang; HEINEN, Norbert (eds.). Basale Stimulation, kritischkonstruktiv. Berlim: Bundesverband f. körper- u. mehrfachbehinderte Menschen, 2006. 